\title{
The economics of use of wireless power supply in electric buses
}

\author{
Michat Filipiak ${ }^{1, *}$, Jarosław Jajczyk ${ }^{1}$, and Arkadiusz Dobrzycki ${ }^{1}$ \\ ${ }^{1}$ Faculty of Electrical Engineering, Poznan University of Technology, Piotrowo 3A, 60-965 Poznań, Poland
}

\begin{abstract}
The article discusses the subject of wireless power supply for battery packs in electric buses. It presents the disadvantages and advantages of such a way to power the vehicle and charge the batteries. An attempt is made at analysing the economic legitimacy of use of this type of energy transfer method. The analysis is based on the annual course of the bus at the level of $70000 \mathrm{~km}$ with the used battery pack whose capacity reaches $250 \mathrm{kWh}$. The assumed life of the system comprised of 2000 charging cycles. The characteristics of energy and losses was drawn up based on the entire life.
\end{abstract}

\section{Introduction}

Wireless power supply has gained more and more popularity mainly because mobile devices in which the transmitted power ranges between 5 and $120 \mathrm{~W}$ are becoming more and more widespread. This type of energy transfer method is also applicable in high power devices. One example here includes electric buses whose transmitted power reaches $200 \mathrm{~kW}$ [1]. In such cases, energy losses, while using inductive charging systems, may constitute a significant part of the energy transmitted into the vehicles (approx. 20\%) [2]. Those losses result mainly from the necessity of using additional power electronic devices, and the lack of galvanic connection between the charging system and the receiver.

A reduction in losses may be obtained by way of optimization of the power supply systems as well as receiver and energy collection circuits $[3,4,5,6]$. Care for their proper technical condition is important $[7,8,9]$. All the actions are aimed at ensuring reliability and the highest possible performance of the system, which will allow for the reduction in the energy demand.

Owing to the wireless charging, the batteries of electric vehicles can be charged while standing at bus stops. By using inductive charging, it is also possible to power and charge vehicles in motion, thus increasing the range and raising the comfort of use [1, 9, 10]. This requires the construction of special lanes on which the vehicles could move. An advantage of this solution is the lack of the necessity of a galvanic connection of the receiver with the power source and the concealment of the infrastructure of the charging system in the road surface.

The article analyses the legitimacy (from the economic point of view) of use of wireless battery charging systems in electric buses.

\section{Operation of electric buses with wireless power supply}

An increase in the number of sold electric vehicles has been noticeable for several years. This trend also refers to electric buses. In order to reduce the pollution coming from the burnt fuel, more and more cities decide to purchase electric buses. One example here is Warsaw, where 136 electric buses were ordered including the infrastructure containing 19 charging points [11]. Such a trend may in not a long time reach other cities in Poland.

The average annual mileage of buses on an urban route amounts to about $70000 \mathrm{~km}$. This translates into the daily mileage, which amounts to about $192 \mathrm{~km}$. In order to extend the life of battery packs, they are charged once a day. Such a manner of operation allows for 5.5 years of their life during the whole warranty period which comprises 2000 charging cycles [12]. In order to cover this distance with a single charge, a bus must have batteries with the minimum capacity which amounts to about $250 \mathrm{kWh}$. The battery capacity used in buses ranges from $60 \mathrm{kWh}$ up to even $660 \mathrm{kWh}$ [13].

A number of variants of wireless power supply systems is used. Among the two-, three- and four-coil systems in vehicles, the two-coil systems are commonly used (often with a ferromagnetic core). An exemplary diagram of such a system is presented in fig. 1. It enables the transmission of high powers at the operating frequency of the system ranging from $20 \mathrm{kHz}$ to about $40 \mathrm{kHz}$. This is a system with the serial-serial resonance on the primary side and serial compensation on the secondary side [10]. $R_{\text {odb }}$ is a system which contains a controller and battery packs.

The implementation of the wireless power supply requires the construction or reconstruction of the power supply system in the bus per se and at the charging site. (e.g. a bus stop). 


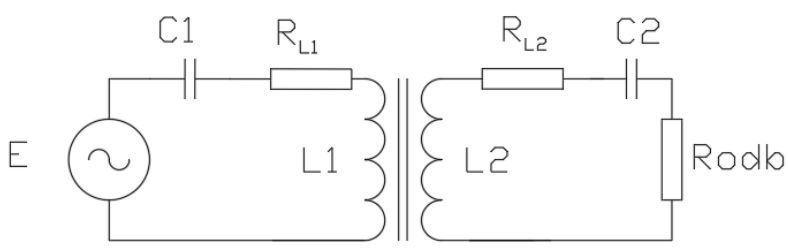

Fig. 1. Diagram of the system for the inductive energy transmission.

This entails the necessity of analysis and effective screening of electromagnetic fields, the impact of which will cover a bigger area than in the case of the conductive charging, especially in the case of the misaligned placement of transmitting and receiving coils $[2,9]$. The imperfect geometry of the transmission system may be the source of additional losses, which leads directly to the necessity of detailed analysis of profitability of use of this solution. Neither can the energy effectiveness of the entire battery charging system be ignored. In the case of wireless systems, the aggregate energy losses are twice as high in comparison with the contact system [1].

\section{Analysis of power losses at wireless power supply of an electric bus}

During analysis of power losses at the wireless power supply of the electric bus, the assumed life was at the level of 5.5 years. With the assumption of the annual course of $70000 \mathrm{~km}$, we obtain the total distance of $385000 \mathrm{~km}$. Figure 2 presents the relationship between the energy supplied to the vehicle and the relationship between the energy losses and the covered distance. The conducted analyses demonstrate the energy losses related to the charging process at the level of about $120 \mathrm{MWh}$ (fig. 2).

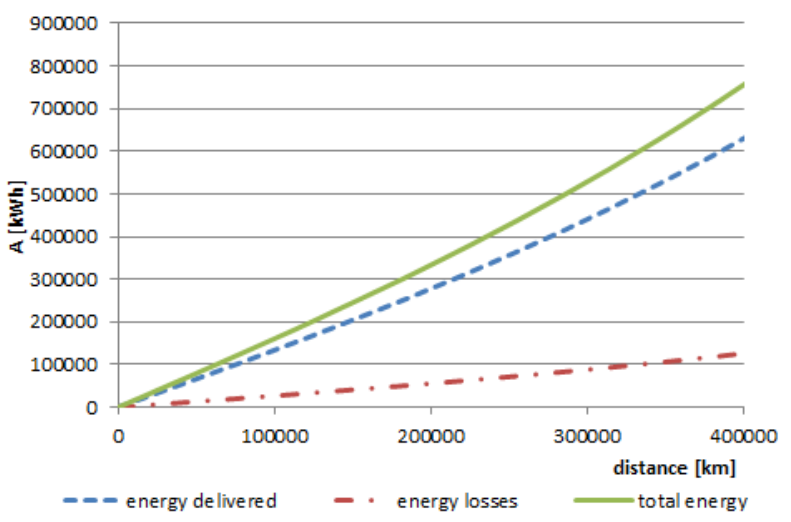

Fig. 2. Energy supplied to the bus and energy losses in the 5.5year life cycle.

Such a way to ensure power supply, taking into account the actual electricity price at the level of $0.12 \mathrm{EUR} / \mathrm{kWh}$, generates additional costs at the level of EUR 15 350. In comparison with the wireless system in which such extensive transmission losses do not occur, these costs will be higher by EUR 7675 .

\section{Summary}

The wireless power transmission technologies are subject to continuous development. Power transmission systems, which are characterized by greater and greater efficiency, are being constructed.

In the case of systems designed to charge the batteries of electric buses, there are problems omitted in the lower power systems, among others, those related to the electromagnetic impact. An important factor which increases the costs of operation is the significance of energy losses related to the powerless energy transmission.

In this paper, the additional costs related to the wireless power transmission throughout the assumed life were estimated at the level of EUR 7 675. The conducted analyses do not comprise the costs of construction and operation of the infrastructure. It is only the knowledge of aggregate investment and operational costs which will allow for the full estimation of the economic legitimacy of use of the wireless electric bus charging system.

\section{References}

1. A. Dobrzycki. M. Filipiak, J. Jajczyk, Pozn Univ Technol Acad J, Electr Eng 92, 25-35 (2017)

2. S. Ahn, J. Kim, Antennas and Propagation (EUCAP), Proceedings of the 5th European Conference, 3979-3982, IEEE (2011)

3. J. Jajczyk, L. Kasprzyk, 6th IASME/WSEAS (HTE'08), WSEAS Mechanical Engineering Series, 226-231, (2008)

4. J. Jajczyk, IEEEXplore Electronic, CPEE 2016 (2016)

5. K. Bednarek, J. Jajczyk, Prz Elektrotech. 85, 29-32 (2009)

6. L. Kasprzyk, Eksploat Niezawodn 19 (2), 229-236, (2017)

7. A. Dobrzycki, S. Mikulski and W. Opydo, 2014 ICHVE International Conference on High Voltage Engineering and Application, 1-4 (2014)

8. W. Opydo, A. Dobrzycki, Pozn Univ Technol Acad J, Electr Eng. 94 (37), (2012)

9. J. Jajczyk, A. Dobrzycki, M. Filipiak, D. Kurz, E3S Web Conf. 1901027 (2017)

10. M. Filipiak, R. Nawrowski, IEEEXplore Electronic, CPEE 2017, 1-4, (2017)

11. Elektryczne autobusy w Warszawie. Docelowo 136 sztuk i 19 stacji do ładowania, http://warszawa.nasze miasto.pl/artykul/elektryczne-autobusy-wwarszawie-docelowo-136-sztuk, dostęp: 10.09.2017

12. M. Andersson, (2017). UPTEC ES, ISSN 1650-8300 ; 17 002, (2017)

13. https:/www.proterra.com/products/40-foot-catalyst/ (access: 08.06.2018) 